\title{
A Large French Wind Tunnel
}

$\mathrm{T}^{\mathrm{H}}$ HE large wind tunnel which has just been completed at Chalais-Meudon is of considerable interest. It is the second tunnel capable of testing a full-sized aeroplane to be constructed, the first being the $60 \mathrm{ft} . \times 30 \mathrm{ft}$. tunnel at Langley Field, U.S.A., and it differs in one very important respect from any other wind tunnel, in that it is built in the open. In general design it is not unlike the tunnel built by Eiffel in 1912 at Auteuil ; a type now generally known by his name. Air is drawn in through a contracting inlet and then passes as a parallel free jet across the observation chamber into a collector cone in which a gradual expansion takes place in order to recover most of the kinetic energy of the stream.

In the older Eiffel tunnels, an airscrew or a centrifugal fan at the end of this expansion cone drew the air through the tunnel, which was itself housed in a large room through which the air returned to the intake end at a low speed. As a single airscrew in the present large tunnel would be of such great diameter, the expansion oone has been allowed to discharge into a large chamber, or 'diffusor', from which the air is extracted by six airscrews, each working in a short expansion cone projecting from the back wall of the chamber. The cross-section of the tunnel is everywhere elliptical, and at the working section is $52 \mathrm{ft}$. wide and $26 \mathrm{ft}$. high. Each of the six airscrews is driven by a 1,000 h.p. variable speed electric motor, and a maximum wind speed of about 110 miles per hour is expected. As mentioned above, an entirely novel feature is that the tunnel is in the open, instead of being housed in a building, thereby effecting a very large saving in the cost of construction.

The new tunnel differs radically from the fullscale tunnel at Langley Field, which is of the return-flow type in which the air leaving the driving airscrew is guided by suitable ducts of gradually expanding cross-section back to the intake end of the tunnel, a type first successfully used by Prof. Prandtl at Göttingen. Such a tunnel is more costly than one of the French type, as there is at least twice as much ducting, but it has the advantage that the air in the tunnel is quite free from external atmospheric disturbances. The power consumption for a given wind speed is less in the return flow type; but, if the figures given for the French tunnel are realised, the difference is not very great and may well be counterbalanced by the lower constructional cost.

The one debatable point about the new tunnel is the advisability of placing such a tunnel in the open air, where the incoming air is subject to atmospheric disturbances. There is very little data on the effect such disturbances will have in a large high-speed tunnel. Some experiments made on a small model of a wind tunnel at the National Physical Laboratory many years ago showed that the disturbances in the tunnel stream were many times as great when the tunnel was in the open, even when the wind outdoors was only a light breeze, than when it was operated in the still air of a large room. This model was, however, very small, and was only operated at the comparatively low speed of $40 \mathrm{ft}$./sec., at which the dynamic pressure is comparable with the pressure changes occurring in a gusty wind of quite low velocity. In the French tunnel the speed is much higher, and moreover, the inlet and outlet ends are separated by many hundreds of feet, a dimension which may be large compared with the average extent of eddies in the atmosphere. It may be mentioned that the tunnel has been placed in a hollow, with the view of shielding it so far as possible, but even with this protection it seems unlikely that it will prove possible to use the tunnel satisfactorily if any considerable natural wind is blowing. It will be exceedingly interesting to learn how the tunnel behaves in this respect, and what is the limiting natural wind velocity at which the tunnel stream is still steady enough for normal measurements.

A great deal might be written on the relative merits of the large tunnel capable of testing actual aircraft, and the alternative of testing scalemodels in smaller tunnels, with guidance on scaleeffect obtained by researches in a compressed air tunnel. There is certainly one field in which the large tunnel should be exceedingly useful. In these days the most marked tendency of aircraft design is towards the reduction of resistance and the attainment of high speed. For investigations with this end in view, the large tunnel offers the great advantage that the actual aircraft can be tested with all its little imperfections, such as roughness of surface and unavoidable excrescences, and that the effect of practicable improvements in such details can be directly determined. In testing small models in normal wind tunnels or in the compressed air tunnel, there is a distinct danger that the finer detail of the actual machine may not be properly represented.

The large tunnel also holds out the possibility of testing the aircraft with its engine and airscrew running, and so of investigating the effect of attempts to reduce resistance without adversely affecting engine cooling. This class of experiment, which is of great importance, is practically impossible on small models, though it can be carried 
out in a smallertunnel than the new French one. The $20 \mathrm{ft}$. tunnel in the United States and the new $24 \mathrm{ft}$. tunnel at Farnborough were, in fact, built chiefly for such work. The cost of running a full-scale tunnel, and of the preparation of machines for test therein, is necessarily heavy, and there is the limitation that even in such tunnels as those at ChalaisMeudon and Langley Field, only a small aeroplane can be tested. The limit of span, without involving large corrections for the constraint of the limited stream, would probably be about $40 \mathrm{ft}$.
In spite of such limitations-and every type of tunnel has limitations of some kind-the new equipment should prove of great value to the French in the study of aerodynamics, and it is to be hoped that results obtained by its use will be available to the world at large. It is only by careful analysis and comparison of results obtained in various types of wind tunnel and on machines in flight that the greatest use can be made of the research work of the various institutions in different countries.

\section{Minute Intergenic Rearrangement as a Cause of Apparent 'Gene Mutation'}

By H. J. Muller, A. Prokofyeva and D. RafFer, Institute of Genetics, Academy of Sciences of the U.S.S.R., Moscow

$\mathrm{W}^{\mathrm{n}}$ HEN it was discovered that chromosome breakage and reattachment usually entail effects resembling those of gene mutations located at or very near the point of breakage, it was suggested, as one alternative interpretation of this phenomenon, that the change in position of genes near the breakage point, with respect to other genes in their immediate vicinity, might in itself be the cause of their altered mode of reaction upon the organism (Muller, 1930). This was an extension of the 'position effect' principle which had previously been proposed for the special case of the bar genes, two of which had been found to have a greater effect when in the same chromosome than when in opposite chromosomes (Sturtevant, 1925). Since 1930, numerous further illustrations have been found, by various investigators, showing the comparative regularity with which effects resembling those of gene mutations in nearby loci accompany breaks, but there has been little or nothing in their evidence that would serve to test the probability of the 'position effect' interpretation as opposed to the alternative conception that the disturbance involved in the process of breakage was of such a nature as to be likely simultaneously to upset and alter (once for all) the inner composition of genes in the vicinity. The senior author has now, however, obtained definitive evidence (see Muller and Prokofyeva, 1934) of the correctness of the 'position effect' interpretation, through the finding that different rearrangements involving the scute locus in Drosophila in the great majority of cases result in phenotypically different 'allelomorphs', whereas nearly identical rearrangements (scute 4 and scute $L 8$ ) have given sensibly the same 'allelomorphs'.

The general question thus arises, what proportion of apparent mutations are only intergenic 'position effects' rather than autonomous intragenic changes? Of twenty-seven scute and achaete mutations investigated which have been produced by irradiation, it has so far been possible to demonstrate in eighteen cases that there was a breakage and re-attachment close to the scute or achaete locus. Some or all of the remainder also are probably intergenic rearrangements, for it has been found in this investigation that the rearrangements tend to fall into two categories, gross and minute, the latter being of such a nature that a genetic discrimination between them and true intragenic mutations would be very difficult, or in many cases even impossible.

One example of a minute rearrangement is scute 19, in which only a fraction of a single chromomere (or chromatin 'ring' number 2, as seen in the salivary gland) has, as shown both by genetic and cytological evidence (see Fig. 1), become deleted, by a break on each side of it within the same chromomere, and inserted into another region of the chromatin (within the right arm of chromosome 2). We accept here Koltzoff's explanation of the structure of the salivary gland chromosomes, as bundles of practically uncoiled chromonemata the adjacent chromomeres of which form the 'rings' or 'dises' (see also Carnoy, 1884, and Alverdes, 1912, 1913) ; our work, however, shows definitely that the genes-usually more than one per chromomere-are contained within these chromomeres. Special genetic and cytological methods explained elsewhere have shown that the displaced section of the chromomere here in question includes only about six (four to eight) genes. This case does not illustrate a method of origination of recognisable 'deficiencies' alone. If such a deficiency included but one or two genes, instead of six, it would in some cases be viable and resemble in its heredity an intragenic mutation, as other work of Muller (in press) has shown. On the other hand, the inserted section, without the deficiency, could be mistaken for a simple genic 'suppressor', especially since, having been weakened in its activity by the effect of its changed 